\title{
The second generation seed orchard research project at the Direction de la recherche forestière in Québec
}

\author{
by Stéphan Mercier $^{1}$ and Pierre Périnet ${ }^{1}$
}

\section{Introduction}

In 1993, a new project was initiated at the Direction de la recherche forestière $(D R F)$ to develop operational technology for the management of second generation seed orchards, including containerized and miniature field orchards. The main objective was to develop operational methods for controlled mass pollination. In 1999 and up to 2007, five new orchards will be established for the production of black spruce and white spruce seeds of the second generation. Intensive orchard management technology (clonal blocks, floral induction, pollen emasculation, pollination, pruning, etc.) still have to be developed for optimizing seed crops.

The goal of seed orchards is to produce high quality seed that optimizes genetic gains from the breeding program and to be economically effective (Sweet 1995). Over the years, research has been aimed at trying to improve seed yields and genetic quality of orchard crops. Controlled pollination has great potential for increasing genetic gains by controlling the male parents and reducing the loss due to pollen contamination. The genetic gain anticipated from these second generation orchards will be significantly greater with controlled pollination. Resorting to artificial pollination is obviously more expensive than open pollination. Nonetheless, artificial pollination represents a major issue since pollen constitutes half of the genetic makeup of the seed crop. In this paper, we present an overview of a research project in this area with emphasis on pollen management, pollination and seed production, and miniature seed orchard management through the use of shelter and windbreaks.

\section{Project Overview \\ Growth Installations}

Research is conducted in eight tunnels and three open areas equipped with drip-irrigation to cultivate the 1900 containerized ramets of spruces and larches in pot-size of 16 , 28 , or 60 liters. Three greenhouses are used for ramet propagation and subsequent growth. Spruce mini-orchards were field-planted in the nursery in 1994, 1995 and 1997, representing 1300 trees and a total area of 2,0 ha. All these installations are located at the Station forestière de Duchesnay, formerly a provincial tree nursery.

\section{Material}

Black spruce, white spruce, and larch grafts have been grown in containers under intensive cultural regimes for rapid crown development, early flowering, and seed production. In 1997, two experimental miniature spruce orchards were planted in the field to test cultural practices and pollination tech-

\footnotetext{
${ }^{1}$ Ministère des Ressources naturelles du Québec, Direction de la recherche forestière, 2700, rue Einstein, Sainte-Foy (Québec) G1P 3W8, Canada.
}

niques. Norway spruce grafts have also been established in containers or in mini-orchards planted in 1994 and 1995 in the nursery.

\section{Cultural Regimes}

Containerized trees are dripirrigated, fertilized using Nutricote and soluble fertilizers, with rootpruning and repotting every other year. Trees are cultivated in the open (full light) except during winter and early spring for pollination when they are kept in polyhouses (tunnels). Trees are grown to the desirable size, with pot size increasing up to 60 liters. Crowns are pruned regularly according to species requirements. The mini-orchards are intensively managed through irrigation, fertilization, weed control, insect and disease con-

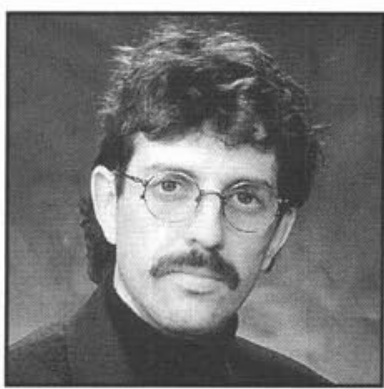

Stéphan Mercier

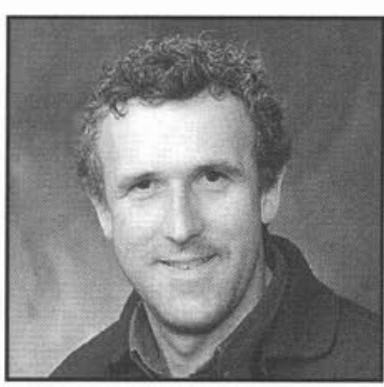

Pierre Périnet trol, cultural practices (root confinement and pruning), and eventually for flower production and controlled mass pollination.

\section{Plant Propagation}

Ramets are usually propagated through grafting. In collaboration with the Direction de la production des semences et des plants and the Pépinière de Saint-Modeste, we developed a method where 10 to 20 -year-old ortets of black spruce or hybrid larch (Larix decidua and L. leptolepis) could now be successfully propagated through rooting of cuttings. This technique allows us to produce more ramets in a single harvest at an earlier stage than grafting, and is more cost-efficient (Tousignant et al. 1995). For example, cuttings from selected trees in 10 year-old progeny tests of black spruce were rooted, repotted in 4 literpots, and will be used for the establishment of the second generation operational seed orchards.

\section{Improved Seed Production \\ Pollen Management}

Over the last few years at the Direction de la recherche forestière, a prototype pollen aspirator was developed for harvesting a large quantity of pollen in a short period of time. This device can recover and sift the pollen directly on the tree at the moment of pollen sac rupture. With this portable device the operator can harvest several hundred milliliters of readyto-use pollen in less than an hour. If an electrostatic pistol is used, the pollen must be dried at $40^{\circ} \mathrm{C}$ for 4 hours before pollination. However, the device's yield is dependent on wind conditions; thus wind should be minimized during the pollen harvest using a windbreak, or the harvest should be carried out on a calm day. 
A pollen bank, established in 1988, provides long term storage of dried pollen. The storage techniques for pollen have been developed for spruce and pine (Mercier 1995a). Pollen of these species can be stored for at least seven years without any apparent change (Mercier 1995b, Colas and Mercier 1996) provided pollen has been dried to a moisture level of less than $10 \%$. To accomplish this, three drying stages are necessary to eliminate free water within the pollen grains and any other water that may have entered when the pollen was bottled. The first drying stage $\left(30^{\circ} \mathrm{C}, 16\right.$ hours) causes the rupture of the pollen sacs, thus freeing the pollen grains. The second drying stage $\left(40^{\circ} \mathrm{C}, 4\right.$ hours $)$ is usually enough to reduce moisture content in the microspores to about $5 \%$. Finally, freeze-drying (soaking for 2 minutes at $-196^{\circ} \mathrm{C}$ followed by freeze-drying at $-65^{\circ} \mathrm{C}$ for 15 minutes) is necessary to eliminate moisture on the outside of the pollen grains and to vacuum-seal the $10 \mathrm{~mL}$ bottles which are stored at $-30^{\circ} \mathrm{C}$.

Research has also concentrated on pollination methods to improve efficiency. Efforts have included the development of a portable model of the electrostatic pistol designed by CEMAGREF in France (Philippe and Baldet 1997). This device pulverizes the pollen in such a manner that a magnetic field is created between the pistol and the tree being pollinated. The negatively charged pollen grains are strongly attracted to the tree, which is grounded. Because female flowers are more conductive than the trunk or branches, the charged pollen is concentrated on female inflorescence, which are coated uniformly due to the electrostatic coating effect. For the last three years, the results have been convincing. Under a shelter, it has been possible to get seed yields in white spruce of approximately 60 seeds/cone, compared to the controls (i.e., a pollination syringe) which yield an average of 30 seeds/cone. Another advantage of this equipment is the small quantity of pollen required; on the average four times less pollen is used than by a conventional compressed air pistol. Research is currently being done to achieve adequate pollination with one application of diluted pollen per cone. This should reduce the volume of pollen required to a quarter of what is presently needed.

\section{Flower Induction}

The gibberellins $\mathrm{GA}_{4 / 7}$ are currently used in experimental seed orchards to induce flowering in black and white spruce. This treatment is particularly effective and, for the time being, we use it on a limited scale. In the future, we plan to inject more trees with $\mathrm{GA}_{4 / 7}$ to accelerate our pollination studies. However, it is important to note that these growth regulators can cause severe stress to trees and that they are expensive. For the time being, cultural practices, including tree fertilization, root pruning, water stress, and crown exposure to light, appear to be a safer, far less expensive method. It is well known that nitrogen significantly influences the number of cones produced, the number of ovules per cone, as well as the size of the seeds and cones. There is uncertainty concerning the effect of fertilization on perdition of female cones and research and development is being carried out on this subject. Another method of inducing flowers in spruce is to expose trees to flashes of red light at night during the spring. This technique seems promising because it is inexpensive and does not seem to cause severe stress.

\section{Reproductive Biology}

Genetic diversity of trees in a seed orchard is much greater than one would find in a natural stand of trees that has crosspollinated for centuries. In fact, seed orchards constitute an artificial regrouping of trees from different origins in which we observe time differences in reproductive bud phenology. The spread observed in the orchards comes largely from that geographical diversity. This spread could also increase the degree of difficulty and the costs of harvesting cones. This same phenomenon is equally observed in the level of pollen dispersion, in the receptivity period of the female inflorescence and in the opening of the cones at the end of the growing season. Studies have thus been started to evaluate the extent of this dispersion and to learn how to manage this phenomenon more adequately in order to reduce the costs of management as well as making the work easier without reducing the quality of the genetic material obtained.

\section{Seed Orchard Management}

For the second generation of genetically improved trees, two seed orchard models are currently being studied at the $D R F$. The first model uses a temporary shelter set up above the trees, while the second uses a windbreak system. It is essential to work out an orchard model that allows artificial pollination on a large scale in an economical manner and with the greatest genetic gain possible.

\section{The concept of sheltered seed orchards}

Work done during the last few years on this project clearly shows that a seed orchard layout in a tunnel combined with artificial pollination offers interesting opportunities for the management of second generation orchards. These opportunities include:

- complete elimination of pollen contamination by using a polyethylene covering at the beginning of spring. This speeds up male and female cone development by 1.5 to 2 weeks compared to natural pollen dispersion. This increases genetic gains and lets the seed orchard be located anywhere, without concern about the composition of adjacent stands;

- significant reduction in the quantity of pollen needed for mass pollination with an electrostatic pistol;

- higher pollen yields using an aspirator as the covering eliminates any wind. In effect, one can harvest pollen or pollinate at any time, even in rainy or very windy conditions;

- greater flexibility during pollination since it is possible to speed up or slow down the development of male and female cones so that interspecific crosses can be carried out, i.e., Larix decidua with L. leptolepis;

- greater ease in carrying out floral induction, protection, pollen harvest, pollination, and cone harvest since the ramets must have small dimensions;

- reduction of male and female cone loss because of freezing (especially wind chill) and bad weather;

- greater flexibility in the clonal mixture since stock management with containers lets one improve the genetic makeup of the seed orchard by adding improved selections as they become available (concept of evolving seed orchards);

- greater flexibility from the layout of the material since it is possible to regroup the clones by their genetic quality and by their phenological stage, thereby reducing the consequences of the dispersion of anthesis and, consequently, achieving 
better management of pollination operations;

- the possibility to move the seed orchards under shelters onto unproductive land or near to a tree nursery where the personnel and facilities can be used jointly, and;

- better growth control of the ramets.

In addition, other opportunities may become more important with time:

- mass pollination inside a tunnel may help reduce the genetic loss due to inbreeding because emasculation would be easier to do and pollination efficiency would be superior compared to outdoors;

- insect control may be improved with the tunnels during the years in which cones are not harvested because the absence of pollination could result in the abortion of female cones. It is also possible to further hasten the development of reproductive buds by leaving the cover on the tunnel for the whole winter as well as April and May. The presence of the cover both protects by limiting damage due to winter freezing and increasing the ambient temperature by eliminating the wind factor. However, research has shown that the cover should be removed immediately after female cones close so as to expose annual shoots to direct sunlight. Actually, we were able to show that the presence of a cover diminishes cone production the following year by reducing light exposure. Thus, it appears to be important to remove the cover immediately after the pollination period and to expose the trees to full light for the whole summer so as to favor the formation of male and female cones the following year. If the conditions are adequate, it is possible, with black spruce - and to a lesser degree with white spruce - to obtain an average production of cones after a good seed yield the year before.

This type of management is particularly effective for improving genetic quality of seed crops. However, the costs of having several thousand containerized trees in conventional tunnels are significant. Noteworthy are the costs of the infrastructure needed for setting up the tunnels and winterizing, periodic removal of snow from the tunnels, forcing, pollination and floral induction, and a reduction of the production potential of cones since the height of the grafted trees is limited by the height of the tunnels. Furthermore, this type of seed orchard requires the use of artificial pollination for seed production and intensive cultural practices.

\section{Using a Windbreak Network}

Windbreaks can significantly reduce wind speed and lead to localized micro-climates which can accelerate ramet development by several days (Anonymous 1978, Guyot 1983). To accomplish this, windbreaks must be arranged in a specific fashion and be spaced at intervals between 50 and 100 metres. The desired objectives of this type of management is to speed up the development of female cones by several days, maintain low costs, and prevent pollen contamination. In addition, a plastic ground cover can eliminate competition and increase soil temperature. Furthermore, use of a windbreak significantly reduces wind velocities, which increases the efficacy of mass pollination and of pollen harvesting using an aspirator system.

To obtain desired results, windbreaks should be a maximum of $60 \mathrm{~m}$ apart in the north-south direction (Anonymous 1978). Moreover, the terrain should be sloped at least $1 \%$ towards the south so as to favor the ramet's exposure to sunshine and to permit cold air to flow away during cold periods. The presence of a natural stand or a mature plantation at least $100 \mathrm{~m}$ in size situated on the north side can also lessen north winds between the months of March and May. This is critical.

The species used for windbreaks should conform to certain criteria. To prevent pollen contamination, the selected species cannot be the same as the species cultivated in the seed orchard. Even if the selected species are different from the one being cultivated in the seed orchard, it must not disperse its pollen during the receptivity period of the species in the seed orchard. This prevents spatial competition at the level of the ovule, competition that results from pollen blocking the opening created by the micropyle. Finally, the selected species should have perennial leaves (or a very dense crown) so as to have the maximum efficiency during the pollination period.

Several studies have demonstrated the advantage of windbreaks for fruit orchards (Anonymous 1978, Charfi 1980, Guyot 1983). In this way, this type of second-generation seed orchard management gives certain advantages compared with openpollinated seed orchards and conventional seed orchards where one plans mass pollination. As well as having several of the advantages found with the temporary shelter system, the closely spaced windbreak system eliminates the costs associated with setting up the tunnel infrastructures and the annual setup and take-down of the covering (significant costs). Moreover, this system lets one reach the full potential of cone production, as there is no limit to the height of the trees.

\section{Conclusion}

Seed orchards are likely to remain an important production method for genetic improvement programs provided they stay competitive (Sweet 1995). Economic effectiveness of intensive orchard management still needs to be demonstrated but the development of new techniques for pollen management, mass pollination, and seed production, including the use of a temporary shelter or windbreak, can enhance genetic quality through controlled pollination and management operations.

\section{References}

Anonymous. 1978. Windbreaks and shelterbelts. World Meteorological Organization, Technical note No. 59.126 p.

Charfi, M. 1980. Contribution à l'analyse de l'influence des brisevent sur les facteurs climatiques et la production agricole en Tunisie. Thèse de Doctorat ingénieur. Université d'Aix-Marseille. Faculté SaintJérôme, France. 166 p.

Colas, F. and S. Mercier. 1996. Détermination et maintien de la viabilité du pollen. Ministère des Ressources naturelles. Direction de la recherche forestière. Service de l'amélioration des arbres. Mémoire de recherche forestière (submitted for publication).

Guyot, G. 1983. Les effets aérodynamiques et microclimatiques des brise-vent et des aménagements régionaux. INRA de Montfavet, France. Mémoire de la Station de Bioclimatologie n ${ }^{\circ} 91.43$ p.

Mercier, S. 1995a. The role of a pollen bank in the genetic improvement of trees program in Québec, Canada. 8th International Palynological Congress, Symposium on pollen banks and genetic ressources. September 6-12, 1992. Aix-en-Provence, France. GRANA 34: 367-370.

Mercier, S. 1995b. Pollinisation de masse dans un verger à graines conventionnel: revue de littérature. Ministère des Ressources naturelles. Direction de la recherche forestière. Rapport interne $\mathrm{n}^{\circ} 400.20$ p. 
Philippe, G. and P. Baldet, 1997. Electrostatic dusting: an efficient technique of pollination. Ann. Sci. For. 54: 301-310.

Tousignant, D., M. Villeneuve, M. Rioux, and S. Mercier. 1995. Effect of tree flowering and crown position on rooting success of cuttings from 9-year-old black spruce of seedling origin. Can. J. For. Res. 25: $1058-1063$
Sweet, G.B. 1995. Seed orchards in development. Tree Physiology 15: 527-530. 